\title{
Identification of Extracts Responsible for the Effect of Tick Reppeling Activity of Turmeric
}

\author{
Wattevidanage J. Perera' ${ }^{1}$, Prasad Senadeera ${ }^{2}$, Parthirage P. D. C. Perera², Derrick R. Kulatunge ${ }^{3}$ \\ ${ }^{1}$ Department of Zoology, Faculty of Natural Sciences, The Open University of Sri Lanka, Nawala, Nugegoda, Sri Lanka \\ ${ }^{2}$ Department of Botany, Faculty of Natural Sciences, The Open University of Sri Lanka, Nawala, Nugegoda, Sri Lanka \\ ${ }^{3}$ Department of Chemistry, Faculty of Natural Sciences, The Open University of Sri Lanka, Nawala, Nugegoda, Sri Lanka \\ Email: drkul@ou.ac.lk
}

How to cite this paper: Perera, W.J., Senadeera, P., Perera, P.P.D.C. and Kulatunge, D.R. (2022) Identification of Extracts Responsible for the Effect of Tick Reppeling Activity of Turmeric. Open Journal of Applied Sciences, 12, 51-58.

https://doi.org/10.4236/ojapps.2022.121005

Received: November 25, 2021

Accepted: January 10, 2022

Published: January 13, 2022

Copyright (c) 2022 by author(s) and Scientific Research Publishing Inc. This work is licensed under the Creative Commons Attribution-NonCommercial International License (CC BY-NC 4.0). http://creativecommons.org/licenses/by-nc/4.0/

\begin{abstract}
Turmeric (Curcuma longa L.) is one of the essential condiments all over the world. Turmeric is an important medicine in the eastern medical systems and its therapeutic properties have been well recorded. Curcumin, commonly called diferuloyl methane (hydrophobic polyphenol), was studied extensively for its biological properties. Sri Lankan turmeric records relatively higher percentage (up to 9\%) of curcumin. The bioactive compounds with insecticidal or pesticidal activity were studied from the Sri Lankan turmeric as there is an increasing demand for natural products to control ticks and fleas in dogs against the chemicals that induce some secondary effects. Fifty grams (50 g) of dried coarsely ground turmeric (Curcuma longa L.) was subjected to sequential extractions with four different solvents in ascending order of polarity using Soxhlet apparatus. The treatments consisted of solvent-fractionated turmeric extracts from hexane, dichloromethane $\left(\mathrm{CH}_{2} \mathrm{Cl}_{2}\right)$, ethyl acetate (EtOAc) and Methanol $\left(\mathrm{CH}_{3} \mathrm{OH}\right)$ dissolved in the water to $100 \mathrm{ppm}$. The test carried out using a modified olfactometer and the degree of repellency of common tick species Rhipicephalus sanguineus was recorded. The hexane extract from dried turmeric powder showed the highest repellence of $80 \%$ whereas other fractions showed lesser repellence. Further studies in the direction of purification, dose dependent repellency and persistency.
\end{abstract}

\section{Keywords}

Curcumin, Modified Olfactometer, Fractionated Curcuma longa L., Sequential, Therapeutic

\section{Introduction}

Turmeric is one of the essential condiments all over the world with a millen- 
nia-long usage record, particularly, in the Eastern culture [1]. Dried and ground rhizome of the plant is the source of turmeric of which the colour is varied from bright yellow to brownish yellow. Particularly, the Sri Lankan turmeric powder is brownish yellow and is distinguishable from the imported turmeric powder which is bright yellow in colour. Turmeric is an important medicine in the eastern medical systems and its therapeutic properties have been identified as anti-inflammatory antioxidant, anticancers [2], anti-rheumatic [3] and antibiotic [3]. Characteristic yellow colour in turmeric is due to curcuminoids [4]. Curcumin, commonly called diferuloyl methane (hydrophobic polyphenol), was studied extensively for the biological properties [4] [5]. Sri Lankan turmeric possesses relatively higher percentage (upto 9\%) of curcumin [6]. Fact that turmeric is a crop that can be cultivated easily in Sri Lanka and is in possession of higher percentage of curcumin makes turmeric a highly prospective crop for bioactive compounds in Sri Lanka.

Turmeric contains a range of bioactive compounds including those with insecticidal, pesticidal or insect repellent activity. As a non-toxic natural material, turmeric offers new option for organic pest control and replacement of mineral oil based synthetic pesticides. The major phyto-constituents of turmeric consist of curcuminoids $(1 \%-6 \%)$, volatile oils $(3 \%-7 \%)$, fiber $(2 \%-7 \%)$, mineral matter $(3 \%-7 \%)$, protein $(6 \%-8 \%)$, Fat $(5 \%-10 \%)$, carbohydrates $(60 \%-$ $70 \%)$. Of the curcuminoids, $60 \%-70 \%$ of weight is curcumin and $20 \%-27 \%$ are dimethoxy curcumin and $10 \%-15 \%$ are bisdemethoxycurcumin [7]. The bioactive compounds with insecticidal or pesticidal activity were reported from turmeric in the form of essential oil such as alpha-pinene, beta-Pinene, Caryophyllene, Eugenol, Limonene [8] turmerone and ar-turmerone [9]. Volatile essential oils of $C$. longa contain a mixture of ketones and sesquiterpene alcohols, the latter mainly based on germacrene and bisabolane skeletons. Although there are some reports on the unstable medical chemistry in the curcumin [7], a range of bioactive chemicals with high prospects are available in turmeric [9].

There is a demand for natural products to control ticks and fleas in dogs as chemical counterparts of them were showed to be ineffective and causing sideeffects in log run [10]. Presence of ticks (ex. Rhipicephalus sanguineus) and fleas in the domestic animals are hazardous to human beings. Bartonella spp. infection which causes long-lasting intra-erythrocytic bacteremia in domestic animals and humans is transmitted by tick and fleas [11]. Domestic animals represent major reservoirs of Bartonella spp., especially in relation to human infection [11].

A preliminary study carried out by the authors of this project showed that solvent extracted from dried turmeric powder showed significant repellence effect on the commonly found ticks of the dogs. This is in conformity with the traditional use of turmeric as insect repellent agent. Accumulation of bioactive compounds in the plants including those of $C$. longa, generally, get varied according to the climatic and genetic factors, harvesting time, soil type, fertiliza- 
tion, drying process, and period of storage [12]. As such, it is more sensible to begin the project with screening different biotypes or ecotypes of the crop for a particular bioactivity. Since the curing process of turmeric seems to be critical for the stability of its bioactive compounds, it is necessary to regulate this step as a prerequisite. Evaluation of toxicity or repellence against target insects and arachnids is the initial stage of developing commercially viable products. The second step of this is systematic bioassay-guided fractionation of active ingredient to identify the active repellent compound/s and carry out the confirmation test for the isolated pure compounds for repellence. It may be required to deploy natural (sesamol, piperonal) and synthetic synergists such as piperonyl butoxide (PBO) or piperonyl cyclonene to substantially increase the efficacy of the active ingredient and reduce its cost [9]. Hence, the objective of the study was to identify insect bioactive compounds, extracted and purified from $C$. longa rhizomes, and to determine their exo-parasitic repellence for commonly found tick and flea species in dogs.

\section{Methods and Materials}

Collection of turmeric accessions were done from five different Districts namely: Bibile, Rathnapura, Ampara, Kaluthara and Galle covering both dry zone and the wet zone Sri Lanka. Five kilograms ( $5 \mathrm{Kg}$ ) of fresh samples of turmeric were collected from each District. Yams were washed thoroughly and drained off the water and air dried for 30 minutes. One kilogram of turmeric was dipped in the boiling water for 20 - 30 min until they were positive for needle check. Then the samples were placed for drying at $50^{\circ} \mathrm{C}$ in incubator until they become hard. After drying the samples crushed and powdered before solvent extraction.

\section{Solvent extraction of turmeric accessions}

Direct sequential extraction was done using $50 \mathrm{~g}$ of the turmeric powder which is used in with $500 \mathrm{ml}$ of Hexane, dichloromethane, ethyl acetate and methanol using the Soxhlet apparatus for about $18 \mathrm{hrs}$. However, same procedure was followed for Dichloromethane, ethyl acetate and methanol as was described in $\mathrm{Ku}$ latunga D. R. (2017). The dried and powdered Curcuma longa L. (Figure 1).

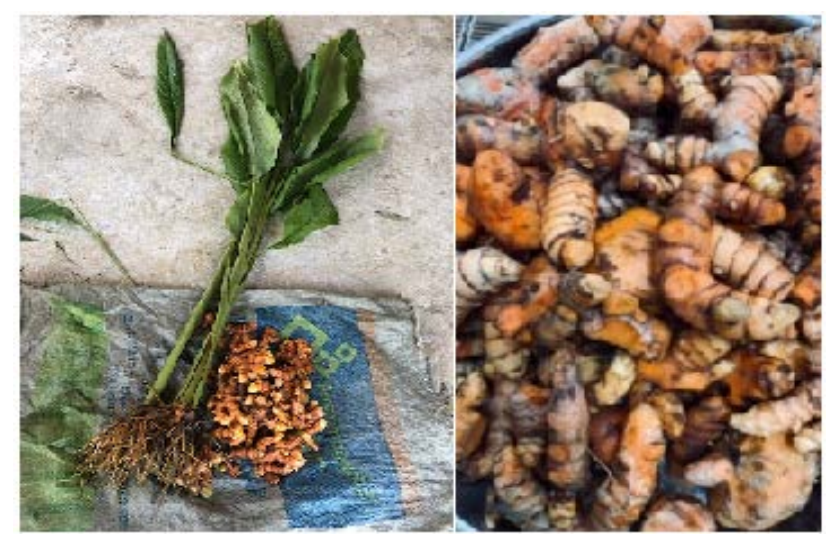

Figure 1. Curcuma longa L. (Yams). 
(Turmeric powder) varieties are extracted using solvents with different polarities sequentially in ascending order starting with hexane, dichloromethane, ethyl acetate, methanol and ultimately water. After filtration, the solvents were evaporated under reduced pressure at $40^{\circ} \mathrm{C}$. The extracts obtained [hexanes extract (DJRS/19/10/01) (0.520 g, 1.04\%) Dichloromethane (DJRS/19/10/02) (1.304 g, 2.60\%) Ethyl acetate (DJRS/19/11/01) (0.963 g, 1.92\%) Methanol DJRS/19/11/02) $(0.876 \mathrm{~g}, 1.75 \%)$ were subjected to Tick repellency activity test.

Those fractions were subjected to TLC (Thin layer Chromatography).analysis carried with solvent $\left(1 \% \mathrm{MeOH} \mathrm{CH}_{2} \mathrm{Cl}_{2}\right)$. Spray reagent used as anisaldehyde.

\section{Modified Olfactometer bioassay}

Tick repellency can be investigated in an air stream using an olfactometer. This modified olfactometer consists of 4 arms. Two of the arms were used for treatments and the other two arms were used for positive control and negative controls Water was used as negative control and commercial preparation of citronella oil was used as positive control. Treatments consisted of solvent-fractionated turmeric extract dissolved in the water and the respective solvent to $100 \mathrm{ppm}$. $500 \mu \mathrm{L}$ from each solution was soaked into $6 \mathrm{~cm} \times 0.5 \mathrm{~cm}$ blotting paper. These soaked papers were air dried at room temperature using a blower for $5-10 \mathrm{~min}$. Blotting paper strips were inserted into the arms of modified olfactometer as shown as in the photograph below. Two of its arms were with the blotting papers soaked with prospective repellent agent dissolved in either solvent (ex: hexane fraction re-dissolved in hexane) or water (ex: hexane fraction dissolved in water). Third arm is negative control (water) while forth arm is the positive control (citronella oil).

Hard ticks (Rhipicephalus spp.) were deployed as an indicator species to evaluate repellence to exo-parasites in dogs. These ticks were collected from the dogs in the university and domestic environments and kept starved for 24 hours prior to the experiment. 10 ticks were inserted from the center of the modified olfactometer. After giving a brief period to settle, the number of ticks in each arm were counted at $1 \mathrm{~min}$ intervals for about $10-12 \mathrm{~min}$. total length of the arms was divided at $7.5 \mathrm{~cm}$ position which is half-way. Ticks that occur beyond the marked position towards filter paper were counted as attracted to it.

\section{Sample preparation for test}

From each extract, $1000 \mu \mathrm{g}$ was dissolved in $10 \mathrm{ml}$ of respective solvent. From this solution $500 \mu \mathrm{L}$ was used to wet blotting paper strip $(6.0 \mathrm{~cm} \times 0.5 \mathrm{~cm})$ which were used for the bioassay. The negative control was prepared using distilled water instead of extracts whereas commercially prepared citronella oil used as the positive control. All the strips were dried for 12 hours at $32^{\circ} \mathrm{C}$ in vacuum oven to remove the solvent (Figure 2 and Figure 3).

\section{Results and Discussion}

Those TLC comparisons with all five districts extracts showed similar type of compounds. Therefore, the five different districts extracts contain similar type of 


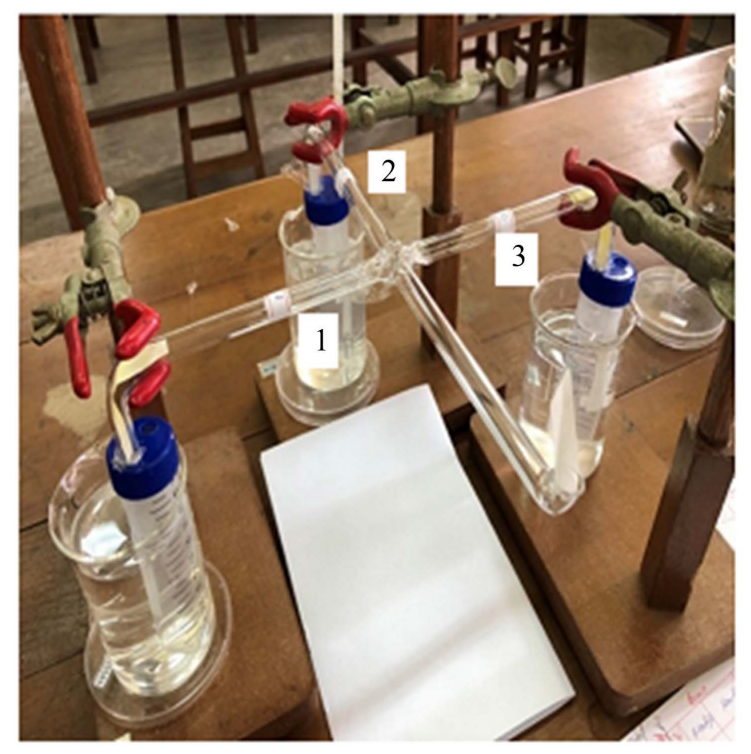

Figure 2. Modified olfactometer used to conduct the Tick repellence Bioassay (Ends of 1, 2 and 3 arms were dipped in $37^{\circ} \mathrm{C}$ water baths to provide thermal attraction for Ticks).

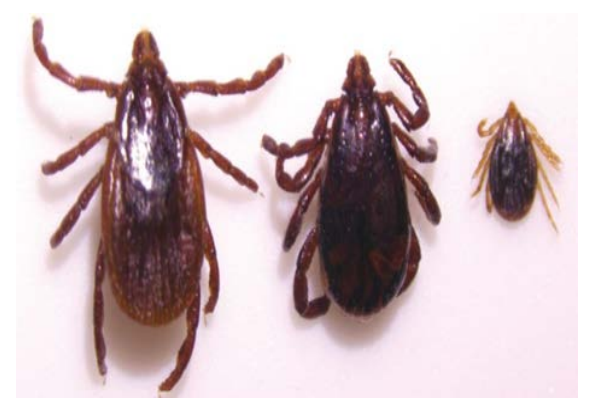

Figure 3. Brown dog ticks (Rhipicephalus spp.).

compounds. Bioassay was done to measure the repellent properties of different solvent extracts of turmeric (Curcuma longa L.) of accessions obtained from Ampara using the method described.

The results indicated that the hexane extract (DJRS/19/10/01) dissolved in hexane and dissolved in water were repelled ticks effectively (Figure 4). Moreover, extract dissolved in hexane indicated the highest repellent properties.

The results indicated that the dichloromethane extract (DJRS/19/10/02) dissolved in dichloromethane and dissolved in water were repelled ticks less effectively than that of hexane (Figure 5). Moreover, extract dissolved in dichloromethane indicated the higher repellent properties when compared with extract dissolved in water.

According to the Figure 6 ethyl acetate extract (DJRS/19/11/01) dissolved in ethyl acetate and dissolved in water were repelled ticks less effectively as in Figure 4. Moreover, extract dissolved in ethyl acetate indicated the high repellent properties comparatively.

The results indicated that the tick repellent properties of methanol extract (DJRS/19/11/02) dissolved in methanol and dissolved in water were poor (Figure 
7). According to above results, both hexane and dichloromethane extracts of Curcuma longa L. have exhibited that repel exo-parasitic arachnids in canine. Bioassay was done to measure the repellent properties of different solvent extracts of turmeric (Curcuma longa L.) accessions obtained from Galle using the method described.

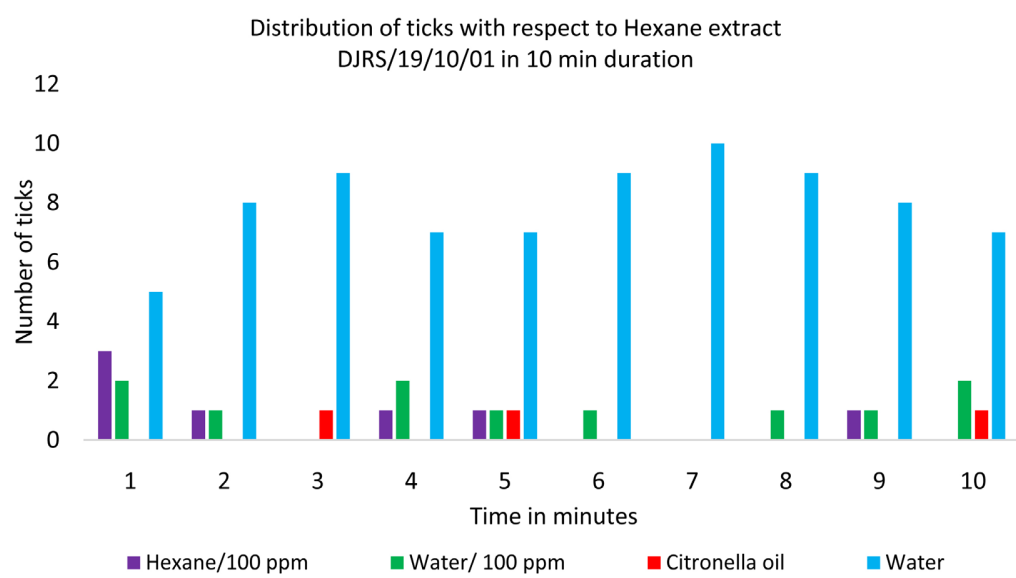

Figure 4. Results of bioassay on hexane extract of DJRS/19/10/01.

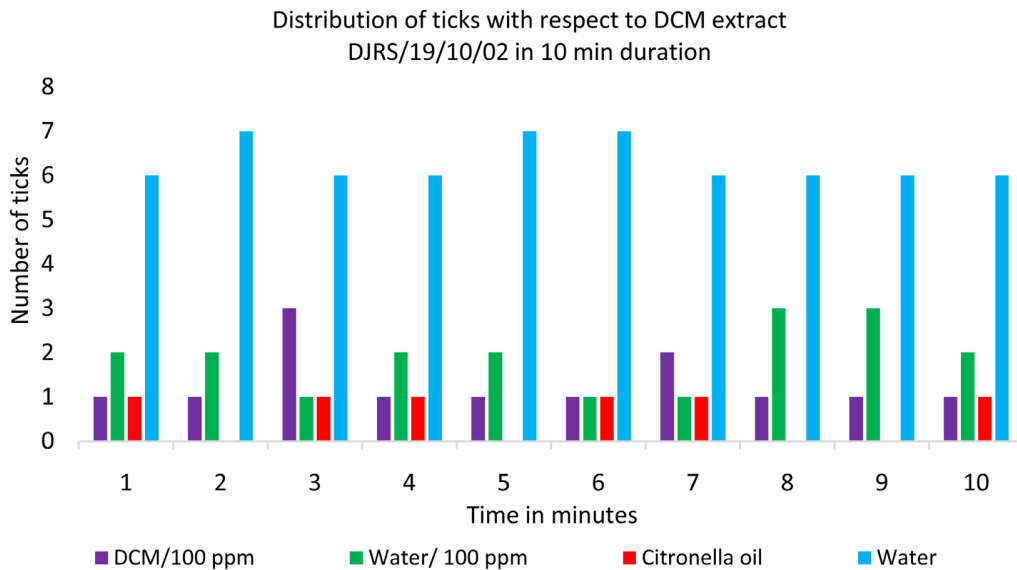

Figure 5. Results of bioassay on dichloromethane extract of DJRS/19/10/02.

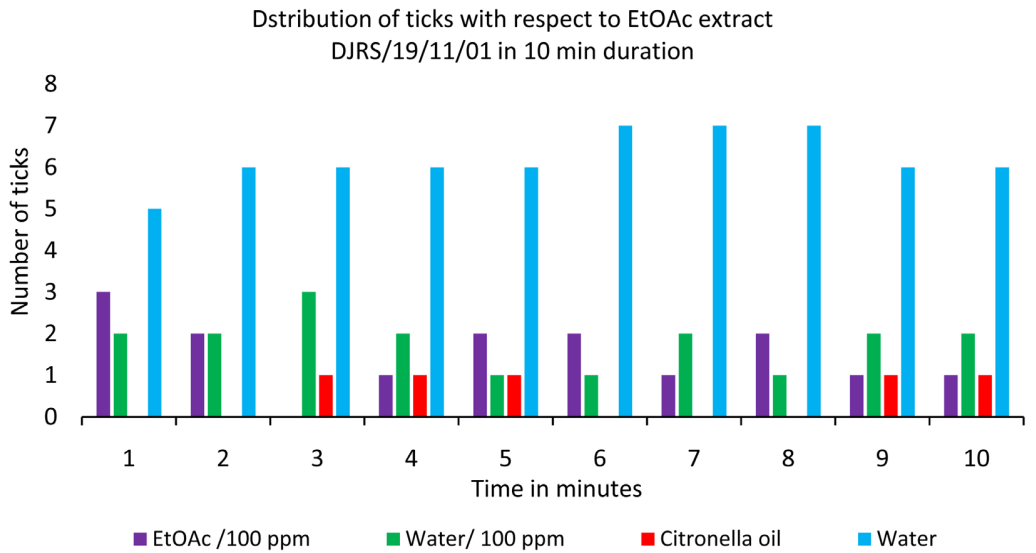

Figure 6. Bio-assay results of ethyl acetate extract DJRS/19/11/01. 


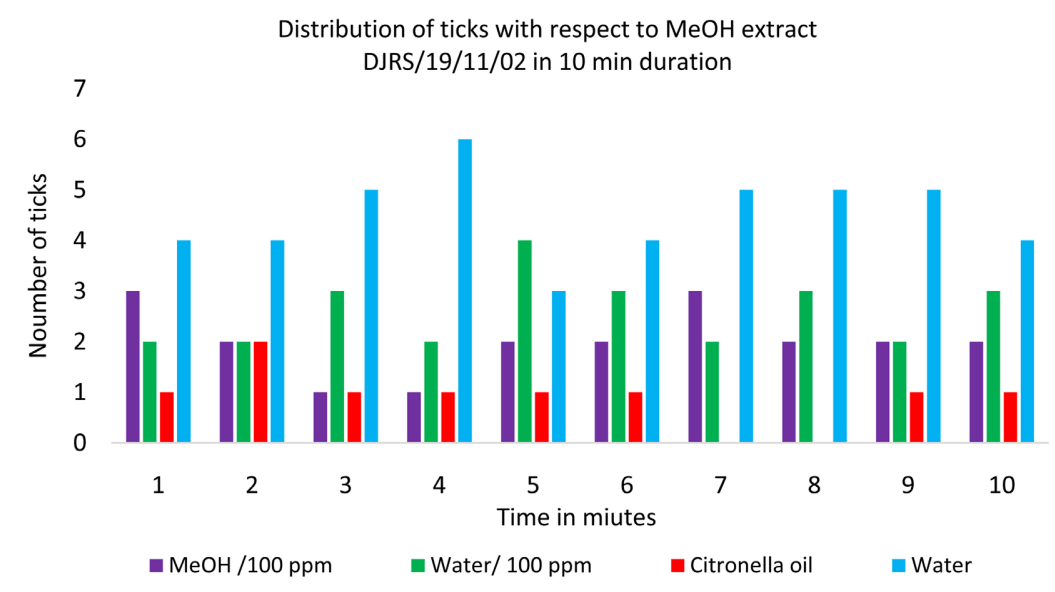

Figure 7. Bio-assay results of methanol extract DJRS/19/11/02.

\section{Conclusion}

- Turmeric demonstrates significant repellence activity for ticks in dogs.

- Turmeric extractions in the hexane showed the highest repellence whereas water extracted turmeric showed the least repellence.

\section{Conflicts of Interest}

The authors declare no conflicts of interest regarding the publication of this paper.

\section{References}

[1] Fallis, A. (2013) Turmeric Genus Curcuma (Vol. 53).

[2] Sharma, R.A., Gescher, A.J. and Steward, W.P. (2005) Curcumin: The Story So Far. European Journal of Cancer, 41, 1955-1968.

https://doi.org/10.1016/j.ejca.2005.05.009

[3] Deodhar, S.D., Sethi, R. and Srimal, R.C. (1980) Preliminary Study on Antirheumatic Activity of Curcumin (Diferuloyl Methane). Indian Journal of Medical Research, 71, 632-634. http://www.ncbi.nlm.nih.gov/pubmed/7390600

[4] Chandra Roy, G., Chakraborty, K., Nandy, P. and Moitra, M.N. (2014) Pros and Cons of Curcumin as Bioactive Phyto-Compound for Effective Management of Insect Pests. American Scientific Research Journal for Engineering, Technology, and Sciences, 7, 31-43. http://asrjetsjournal.org/

[5] Tayyem, R.F., Heath, D.D., Al-Delaimy, W.K. and Rock, C.L. (2006) Curcumin Content of Turmeric and Curry Powders. Nutrition and Cancer, 55, 126-131. http://www.encognitive.com/files/Curcumin $\% 20$ Content $\% 20$ of $\% 20$ Turmeric\%20an d\%20Curry\%20Powders.pdf

[6] Export Agriculture Department of Sri Lanka. Turmeric. http://www.exportagridept.gov.lk/web/index.php?option=com content\&view=artic le\&id $=138$

[7] Kathryne, K.M., Nelson, J.L., Dahlin, J., et al. (2017) The Essential Medicinal Chemistry of Curcumin. Journal of Medicinal Chemistry, 60, 1620-1637.

[8] Yadav, R.P. and Tarun, G. (2017) Versatility of Turmeric: A Review the Golden Spice of Life. Journal of Pharmacognosy and Phytochemistry, 6, 41-46. 
http://www.phytojournal.com/archives/2017/vol6issue1/PartA/6-1-17-211.pdf

[9] De Souza Tavares W, Akhtar Y, Gonçalves GLP, Zanuncio JC, Isman MB. (2016) Turmeric Powder and Its Derivatives from Curcuma longa Rhizomes: Insecticidal Effects on Cabbage Looper and the Role of Synergists. Scientific Reports, 6, Article ID: 34093.

[10] PetMD (2008) Flea and Tick Medicine Poisoning in Dogs. http://www.petmd.com/dog/conditions/neurological/c multi pyrethrin pyrethroid toxicity\#

[11] Brenner, E.C., Chomel, B.B., Singhasivanon, O.-U., et al. (2012) Bartonella Infection in Urban and Rural Dogs from the Tropics: Brazil, Colombia, Sri Lanka and Vietnam. Epidemiology \& Infection, 141, 54-61.

[12] Bansal, R.P., Bahl, J.R., Garg, S.N., Naqvi, A.A. and Kumar, S. (2002) Differential Chemical Compositions of the Essential Oils of the Shoot Organs, Rhizomes and Rhizoids in the Turmeric Curcuma longa Grown in Indo-Gangetic Plains. Pharmaceutical Biology, 40, 384-389. https://doi.org/10.1076/phbi.40.5.384.8458 